\title{
Impact of Social Globalization on the Economy and FDI of Mali
}

\author{
Diadie Sacko \\ School of Economic and Management \\ E-mail:ssacko75@126.com \\ Zhejiang SCI-TECH University \\ Hangzhou \\ China \\ Supervised by CHENG HUA \\ E-mail: chenghua@zstu.edu.cn
}

\begin{abstract}
Currently Mali is open to international economy by liberalizing its investment and trade regimes with the expectation that it will rise economic growth and improve the living standard of the poor, but unfortunately, Mali has evidently failed to take advantage of the opportunities offered by the globalized economy: the country receives a little foreign investment, the maximum value Capital investment, by billion USD for Mali in the period of 2012 was 1.68 billion US dollars, the country fail to produce many processed goods for export, and makes less profit than almost any other countries of the world. Foreign direct investment in Mali has been largely confined to the natural resources especially mineral extraction. This study is an attempt to critically analyze the impact of globalization on the economic development of Mali. The research study adopts descriptive statistics, regression analysis and correlation employed to examine the relationship between globalization and economic growth and between globalization and inequality, recommendations are also given to Mali not be a victim of globalization.
\end{abstract}

Keyword: Globalization, developing countries, economic growth, FDI, hindrance

\section{Introduction}

In the late 19th century and early 20th century, the integration of the world's economies and cultures grew very quickly. The term globalization has been in increasing use since the mid-1980s and especially since the mid1990s. In 2000, the International Monetary Fund (IMF) identified four basic aspects of globalization: Trade and financial transactions, Capital economics and investment movements, Human migration and movement of people and the Dissemination of knowledge.

During 1980s to 1990s Mali sharply curtailed quantitative controls on imports and brought down tariff rates and eliminated restrictions on foreign direct investment (FDI). FDI flows to Mali have increased steadily in recent years and have settled around USD 400 million. The Malian government has been implementing a strong policy to promote FDI for the past several years. It also encourages competitiveness and the participation of the private sector in nearly all sectors. The government participates in foreign involvement, concerning commerce and privatization. Mali underwent economic reform, beginning in 1988 by signing agreements with the World Bank and the International Monetary Fund. During 1988 to 1996; Mali's government largely reformed public enterprises. Since the agreement, sixteen enterprises were privatized, twelve partially privatized, and twenty liquidate. In the late 19th century and early 20th century, the integration of the world's economies and cultures grew very quickly. The term globalization has been in increasing use since the mid-1980s and especially since the mid1990s. In 2000, the International Monetary Fund (IMF) identified four basic aspects of globalization: Trade and financial transactions, Capital economics and investment movements, Human migration and movement of people and the Dissemination of knowledge.

During 1980s to 1990s Mali sharply curtailed quantitative controls on imports and brought down tariff rates and eliminated restrictions on foreign direct investment (FDI). FDI flows to Mali have increased steadily in recent years and have settled around USD 400 million. The Malian government has been implementing a strong policy to promote FDI for the past several years. It also encourages competitiveness and the participation of the private sector in nearly all sectors. The government participates in foreign involvement, concerning commerce and privatization. Mali underwent economic reform, beginning in 1988 by signing agreements with the World Bank and the International Monetary Fund. During 1988 to 1996; Mali's government largely reformed public enterprises. Since the agreement, sixteen enterprises were privatized, twelve partially privatized, and twenty liquidate. 


\subsection{Literature Review \& Understanding Globalization in Mali}

\subsection{Understanding Globalization in Mali}

Globalization could be partially defined as the interaction of activities by many countries across the globe. These activities may include economic investments, sporting activities, internet communications, cultural activities, security, employment opportunities, and many other forms of interaction with in countries over the world. Today, there are many Malians, many Africans, or people from other continents who are living, traveling, or are in a part of somewhere else, which is not their own country. The world is fast becoming a globalized culture, forming its very own unique set of rules, patterns, and lifestyles. The young boys and girls in Mali, or Africa are behaving like western of oriental young. Their way of dressing has changed due to the movies they watch from Latin America, from India, or from Europe. Nowadays people use more resources than ever before, when we were kids, there was no TV in towns, no phone, no internet, no car, no factory, or gold mine in the villages, or around; people are richer than ever before, this has resulted in climate change and a serious diminution of Mali's natural resources. Nowadays we can see Chinese products everywhere in the world, everywhere in Mali, that means, products from Asia are becoming more and more popular because of globalization. In 2000, the International Monetary Fund (IMF) identified four basic aspects of globalization: Trade and Financial transactions, Capital economics and Investment movements, Human migration and movement of people and the dissemination of Knowledge. Global movement of people, goods, and ideas expanded significantly in the following centuries.

Globalization means, I'm a part of you, and you are part of me, we are all affected by globalization even the villagers of Leya (a village) in Mali are also affected in one way or the other. Let's look around ourselves and more importantly at villagers of Leya in Mali, they are using tractors from China, watching television set from South Korea, riding bicycle and motorcycles from China and India, using solar panels and solar torches and lamps from China, eating rice from Thailand; all these products are not local, they are essentially foreign. For example, the clothes that I wear are made in China out of Malian cotton, the Apple phone I'm using is American brand, the most important accessories (chip) of this phone is made from Colten imported from Democratic Republic of Congo, while the cover of the same phone is made with the rubber from Ivory Coast (West Africa). Though the assembly of this dual sim Samsung phone is done in China, most of the accessories of this phone also have been made by other Asian countries and exported in China. If we go to Mali, to Nepal, Panama, to Albania, or to Australia, we will find this original Apple phone similarly at the same price. Most of the music I listen in my iPad (US brand) made in China factories with German, or British engineers are Indian, Ethiopian, or oriental music. I studied my Master in Chinese language and in Chinese university (China Government Scholarship). In Mali the educational system is French system, so in primary school, we studied in French. We can easily buy things that are not produced in Mali or can watch a movie that is foreign. The examples are countless and those given here are enough proof of the fact that globalization exists. However, to fully understand the concept of globalization and whether it is good or bad for a particular country, we need to study thoroughly. The goal of globalization is to provide organizations and countries a superior competitive position with lower operating costs, to gain greater numbers of products, services, and consumers. This approach to competition is gained via diversification of resources, the creation, and development of new investment opportunities by opening up additional markets, and accessing new raw materials and resources. Globalization can open markets, create business, and allow communicating efficiently and effectively with partners, suppliers, and customers and managing better their supplies, inventories, and distribution network. Local producers can sell their products in distant markets with the same ease and speed as in their home country. Everything about our world is a result of globalization, it is very difficult for us to control this situation, we can never get that back. We can only choose what is good.

\subsection{Literature Review}

Many scholars think that Globalization has brought in new opportunities to developing countries, greater access to developed country markets and technology transfer hold out promise improved productivity and higher living standard. Researchers have long been interested in determining the factors of economic development in Sub-Saharan Africa especially in Mali and how globalization affects growth, development. Some scholars have argued that the overall effect of globalization is positive for developing countries whether by trans-border or international integration (Meagher, 2003). Most economists agree that globalization provides a net benefit to individual economies around the world, by making markets more efficient, increasing competition, and spreading wealth more equally around the world. Santarrelli and Figini (2002), defined it as a historical process driven by technology factors such as development of computers and the internet, which reduces the distance between people in terms of space and time. Globalization has reduced barrier existing in international trade. The reduction in those barriers has opened the door for exported growth. On the contrary, other scholars maintain that African nations do not have the potential to effectively integrate into the global economy. 
A major concern is that while other emerging market economies have benefited from globalization, African countries continue to be marginalized (Oshikoya, 2008). Meagher (2003) concluded in her study that globalization, for example, tended to stimulate rather than eliminate illegal and counterproductive activities across Africa. She points out that, as a direct result of unstable and short-sighted political and macroeconomic policies, Africa is mismanaging globalization rather than capitalizing on the net benefit of globalization. In addition, Africa does not have an adequate political and economic infrastructure to effectively manage globalization, therefore reinforcing its global position as economically disadvantaged.

Many people who are concerned about the fate of the world's poor now attribute their plight to globalization. They argue that globalization has weakened the position of poor countries and exposed poor people to harmful competition. Their concern is understandable, especially since the gap between rich and poor has indeed become more glaring in recent decades. However, proving a direct link between economic globalization and poverty is a complex task for several reasons: Interdependence, Globalization leads to interdependence between nations, which could cause regional or global instabilities, if local economic fluctuations end up impacting a large number of countries relying on them. National Sovereignty. Some see the rise of nation states, multinational or global firms and other international organizations as a threat to sovereignty. Ultimately, this could cause some leaders to become nationalistic or xenophobic equity distribution. Indeed, many economists agree that the route to the global economy remains straightforward, most pointedly, as noted above, through trade and investments. Yet Africa's entry into the global markets is complicated by its poverty, debts, and great dependence on natural resources.

\section{Why Globalization not helpful for the Economic Development in Mali}

Globalization itself is not wrong, but its propellers are, who are turning it to a death race where stronger players are more likely to survive and the weaker are the hapless participants. Free trade, the pillar of globalization, has had so many sweet dreams to poor countries, and has ended up in destroying people's own dreams. Today's Mali has more billionaires and hungrier people than any time in history, more children going to mines instead of schools to provide cheap labor, more carbon being and mercury freed from natural reserves and emitted anew. Yet, a drastic fall in child mortality rate and increased life span is also attributed to globalization. Thus, globalization is a paradoxical process, which leads to many critics.

The global market has largely been out of reach for Mali, many of the effects of globalization have already hit this country where most of its ten million people, or more than 80 percent of Mali's population, are living in poverty, inequality, exclusion, discrimination, and unemployment. The structural adjustment programs of the International Monetary Fund and the World Bank, designed to help Mali put its economies in order and encourage investment and growth, have not only failed to address poverty, they have in many instances deepened it. Education and health budgets have been drastically reduced, majority of people of access to basic public services. Millions of people have been thrown into the precarious informal economy, deprived of social protection, they just manage to survive. Globalization has cause the countries to lose their identity like their culture, thought Globalization has propagated economic opportunity, elevated human rights and improved access to information, technology and goods for people in Mali, but these benefits have come at a steep price: the sacrificing of Malian cultural identity for Western ideals. In Mali Globalization can be understood as the development of hybrid cultures, it is actor of the spread of materialistic values. The internet allows any person to access any kind of movie, social website and no one is there to stop, control, or direct you. This has enormous influence on how people think, act, or behave in Mali. The values that this entertainment industry reflects often promote materialism, violence, corruption, debauchery, drug and immorality.

\subsection{Privatization of State-owned enterprises}

Since 1991, Mali government, often under pressure from creditor institutions to act quickly, has sold off hundreds of state-owned enterprises. According to the proponents of privatization, the goal is to cut waste, improve economic efficiency, stimulate the private sector, and mobilize more foreign and domestic investment. However, the process has been fraught with problems and controversy, causing governments to proceed more carefully. In 2007, the Malian government conceded the railroad company to CANAC (a Canadian company), since then it is being the ordeal for the population, 800 persons has been fired and 26 cities and villages of 38 where the train used to stop were canceled. The socio-economic impact of this privatizations is too much because most of the young peoples immigrated to other counties or over areas of the country for better life, the farmers were not able to export their agricultural product to others areas as before so the rate of poverty increase very fast. Moreover, EDF (Energy du Mali) conceding does not improve the electrical problem in Mali, on the other hand the price of electricity was increase and we know in Mali the wage never increases since 30 years. Now, the Energy of Mali adopting the system of pre-paid meters that means you have to pay first electricity before using it. How this can be done in a country where most of the population is very poor, and can't even eat as they want. 
The increase in electricity rates has meanwhile been imposed by the IMF in the Letter of Intent of 2 December 2015. Without the ability to get the energy privatization in Mali, the IMF has been able still force rising electricity prices on $1^{\text {st }}$ July 2016. At the time when populations are demanding the decline old tariffs, the IMF gives the stab in the back of impoverished populations.

\subsection{Foreign Trade}

Mali's share in international trade is small and continues to decline, its market is facing the export of primary products and import of non-primary. With the liberalization of international trade and increased interdependence of national economies, Mali can expect that the competition is fiercer in the field of exports of manufactured goods and primary products. The dependence of Mali on the outside for most of its food has increased so rapidly. Most imports of energy products are extracted from Mali, exported and then re-imported after transformation at a much higher prices. According to the World Trade Organization, trade represented 76.54\% of Mali's GDP from in 2017, the top five export categories for Mali in 2017 were: pearls, precious stones, metals, coins etc. Cotton, live animals 5.9\%, boilers, machinery, nuclear reactors, mineral fuels, oils, distillation products etc.

\subsubsection{Mali Major Trading Partners}

The top three countries to which Mali exports merchandise, along with percentage of exports are: China (26.7\%) Thailand (10.7\%) Denmark (6.4\%) The top three countries which import merchandise to Mali, along with percentage of imports are: Senegal (13.1\%) France (11.4\%) Cote d'Ivoire (11.2\%) The economy of Mali is mostly based on Cotton (First cotton producing country in Africa) 700,000 tons and Gold (Third cotton producing country in Africa), unfortunately the price of cotton and gold is given by developed countries not the state of Mali. World prices and demand for African countries including Mali's cash crops have fallen since 1980s. In addition, competition from intensive capitalist agriculture in Asia and Latin America has further exacerbated the plight of Malian and African farmers.

Figure 1: Mali Trade Openness from 1991 to 2017

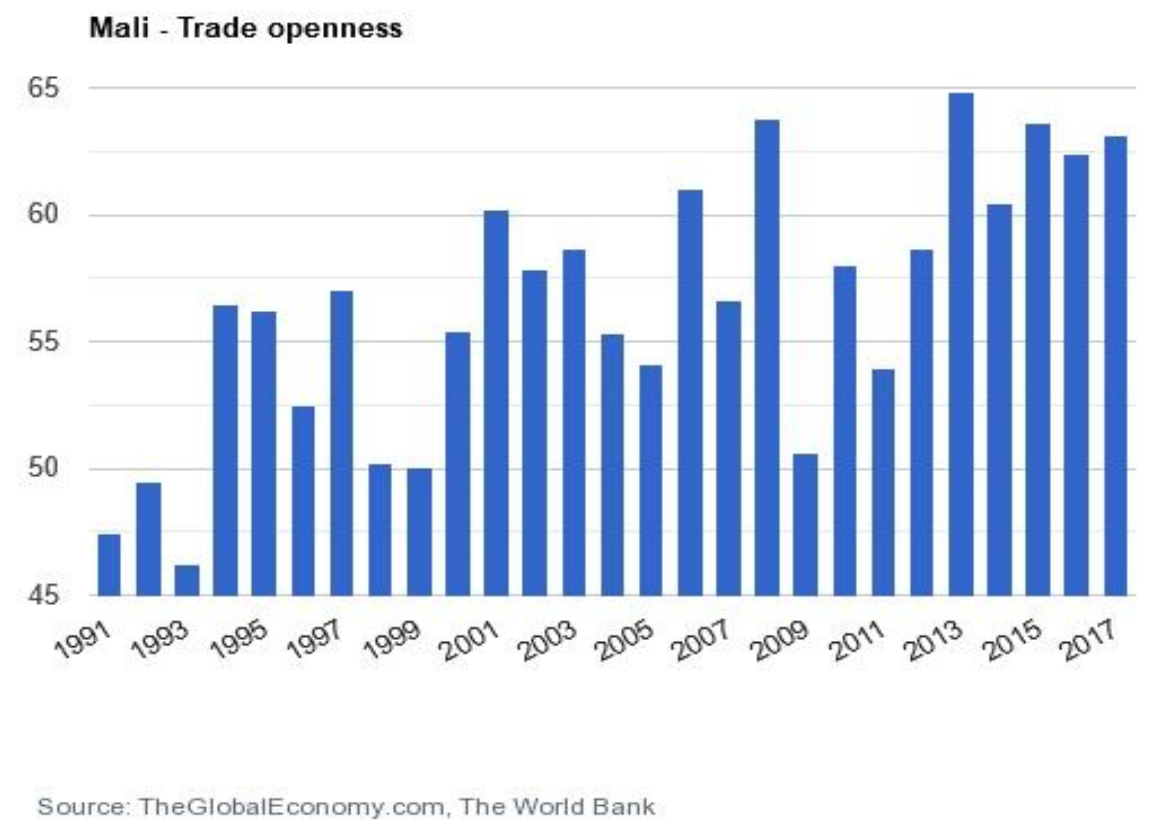

Mali Trade openness exports plus imports as percent of GDP: For that indicator, The World Bank provides data for Mali from 1967 to 2017. The average value for Mali during that period was 49.21 percent with a minimum of 29.32 percent in 1968 and maximum of 64.84 percent in 2013.

\subsection{Social Globalization and Foreign Direct Investment (FDI)}

The expansion of global capitalism policies has been promoted by northern governments and international organizations arguing in favor of an opening of economies to FDI, and by developing country governments implementing more and more open policies. 
The introduction of economic reforms by the Malian government in 1991 led to a sharp increase in FDI flows into the country a few years later. Between 1985-1995, Mali attracted a paltry $\$ 5$ billion in foreign investment per annum. However, between 2000-2016, this figure rose to \$0.65 billion US dollar in 2009.

Figure 2: Mali Social Globalization from 1973-2015

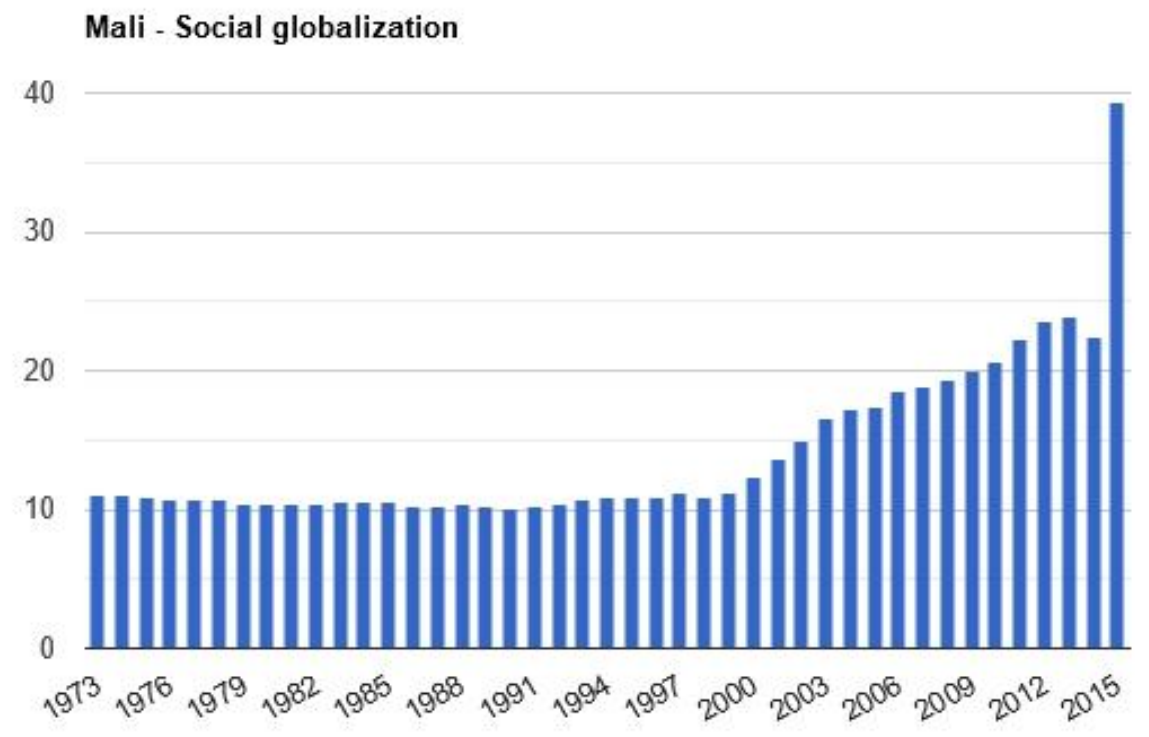

Source: TheGlobalEconomy.com, The Swiss Institute of Technology in Zurich

Mali's main investing countries are France, China, Thailand, and South Africa. Morocco has also been an important investor in the country (banking and telecommunications) since 2010. More than 170 French firms operate here in fields that include electricity, gas, water, oil retailing, steel, glass, cars, bicycles, beer, computers, manufacturing, food processing, tobacco, matches, public works, accounting and insurance. A high profile French investment was the purchase of Bamako's leading hotel, L'Amitié, by the Sofitel chain (SocieteLafico-Mali SA) when it was privatized in 2001. This was followed by a lavish four-star renovation estimated at costing XOF 12, 6 billion, according to the National Investment Promotion Centre and UNCTAD. In 2001, the country's second cellphone operator, Ikatel, owned jointly by France Telecom's (80\%) and private Malian capital (20\%), invested XOF 113, 7 billion in expanding its operations. However, the dominance of French investment is fading in view of the many new entrants into the Malian market. Chinese companies have invested in cotton, sugar, agro foods, textiles, public works, and pharmaceuticals, about 30 Canadian firms now operate in mining, construction, Internet services, publishing, and railways. While German firms have invested in a luxury hotel, solar energy, real estate, and metals. South African, Canadian, Australian, and Japanese firms are the main investors in mining. The major foreign firms in Mali are Mobil Oil (US), Total (France), IPS from the Agha Khan group (US), IAM-Gold and Mink Minerals (Canada), AngloGold Ashanti and Randgold (South Africa), Mercedes-Benz and Chrysler (Germany), Renault (France), Covec and CSCEC (China), Maersk (Denmark) and Yoongpoong (South Korea). From the 262 industrial firms currently operational, 7.25\% are wholly owned by foreigners and $12.22 \%$ are joint ventures between Malians and foreigners. Other prominent foreign players in the economy include the South African parastatal, Eskom, which manages the regional hydrothermal power station at Manantali. As already noted, Manantali supplies electricity to Mali, Mauritania and Senegal.

The foreign direct investment (FDI) should brought in new opportunities, greater access to Mali markets and technology transfer hold out promise improved productivity and higher living standard to Mali. There are some foreign construction companies when coming in Mali for a project like Chinese Comapany, they even bring their own bricklayer, and instead to hire local driver, they drive themselves so there is no job creation or any transfer of technology. Many foreign companies have invested in the country in mining sector particularly in gold mining. This gold mining has led to an environmental disaster and human rights violations. 
Figure 3: Mali FDI 1991 to 2017

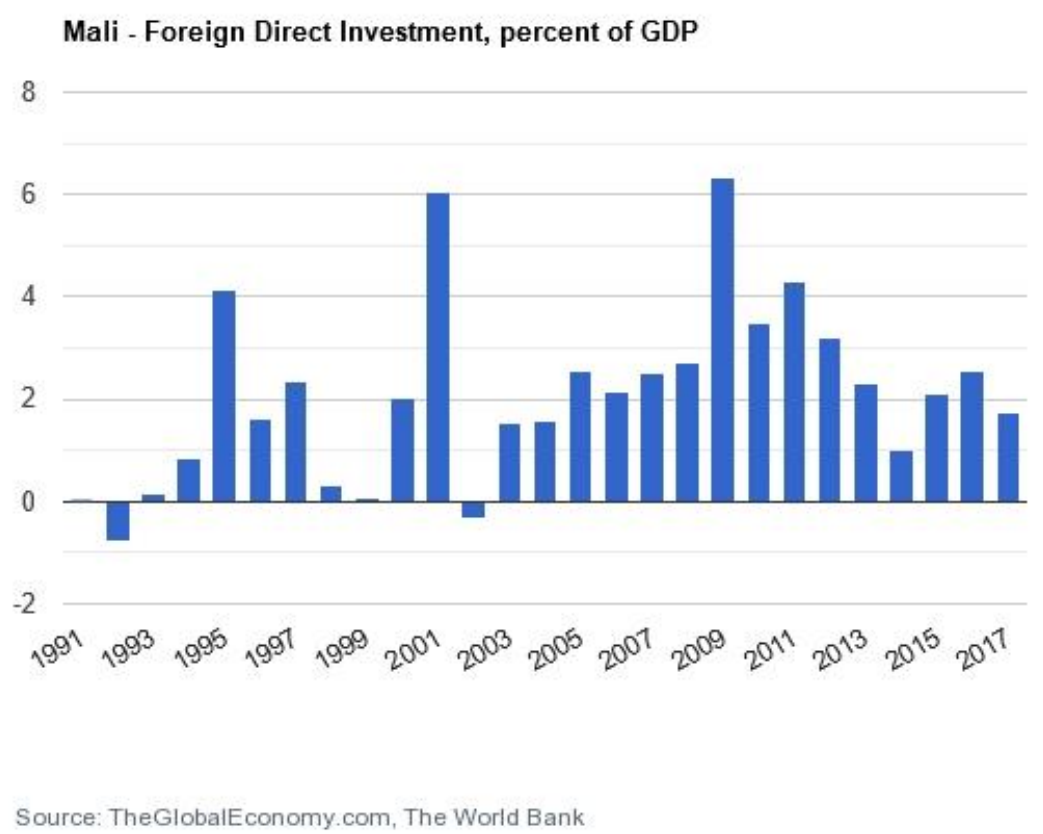

Mali Foreign Direct Investment, percent of GDP, for that indicator, The World Bank provide data for Mali from 1991 to 2017. The average value for Mali during that provide was 1.28 percent with a minim of -0.04 percent in 1991 and maximum of 6.35 percent in 2009.

\subsection{Empirical Study of Globalization and Development, Poverty and Inequality}

Social Globalization and its linkage with economic growth and income inequality between countries and within countries over the past decade had degenerated to a lot of controversies among scholars and policymakers. Various studies had proven that globalization increases growth as well as widening income inequality between countries and even within countries of the world, whereas other numerous studies found that globalization had reduced income inequality within countries as well as equal growth between countries.

\section{Methodology}

\section{Model Specification}

The model I used in this study was adapted from the works of Agene (2003) and Mahler (2001) who looked at the relationship between income inequality and the main modes/set of globalization, such as economic globalization, political globalization and social globalization between, or within country, or region across countries. The model II also took a lead from the Mundel Fleming model of open macroeconomic, which advocated that the more open an economy, the higher the rate of economic growth.

This openness model is expressed in a function as:

$\mathrm{Y}=\mathrm{f}(\mathrm{t} / \mathrm{y}, \mathrm{r}, \mathrm{mg}, \mathrm{f} / \mathrm{y}, \mathrm{in}, \mathrm{dps})$

Where

$\mathrm{Y}=$ Growth rate of GDP

$\mathrm{T} / \mathrm{y}=$ Index of Trade Openers, i.e. total trade to GDP

$r=$ real exchange rate

$\mathrm{mg}=$ real growth of money supply

in = Inflation

dps $=$ Degree of Political Stability

Base on the empirical and theoretical framework models examined. This study derived two models specification to examine the impact of Economic Globalization on economic growth and income inequality in Mali, as represented in equation (1 and 2) below:

INEQit $=\propto+\beta$ Vit + eit 
RGDPit $=\propto+\beta$ Vit + eit

Where INEQ it is the depend variable, representing the income inequality measured by GINI coefficient variable Visit a non-constant vector of I regression for $\mathrm{i}=1,2 \ldots \mathrm{t}$.

Thus, for our empirical estimation, the two models of this study were expressed in the subsequent section.

\section{Model I}

$\mathrm{INEQ}=\mathrm{f}(\mathrm{TGLOB}, \mathrm{FGLOB}, \mathrm{DPS}, \mathrm{FB}, \mathrm{CESS})$

The OLS linear regression equation based in the above functional relation was written as:

$\mathrm{INEQ}=\beta 0<0 ; \beta 1 \mathrm{FGLO}+\beta 2 \mathrm{FGLOB}+\beta 3 \mathrm{DPS}+\beta 4 \mathrm{FB}+\beta 5 \mathrm{CESS}+\mathrm{U}$ eqn

Apron expectation of signs of parameters are stated below:

$\beta 0<0 ; \beta 1<0 ; \beta 2<0 ; \beta 3<0 ; \beta 4<0 ; \beta 5<0$

$\beta 0<0$ is supported by the Dualist Economy Theory that advocate that if all the workers had been the rural area and engaged an agriculture then income of workers would had been relatively equal.

Both $\beta 1$ and $\beta 2$ are accepted theoretically to be $<$ because of assumption of neoclassical growth theory who globe. While other parameters of $\beta 3, \beta 4$ and $\beta 5$ all were expected to be less than $(<0)$ which assumes reduction in income inequality within the country.

INEQ = Income Inequality is proxies as Gini coefficient of Mali, derived from World Bank Development Indicators.

TGLOB $=$ Trade Globalization, otherwise known as Trade Liberalization, proxies as sum of total exports and Imports as a ratio of RGDP.

FGLOB = Financial Globalization proxies on the ratio of FDI to RGDP.

DPS = Degree of Political stability, which measures the number of years of democracy in the country. The presence of democracy is coded as " 1 " while non presence of democracy is coded as " 0 ".

$\mathrm{FB}=$ Fiscal Balance proxies as index of Good Governance.

CESS = Capital Expenditure on Economic Services, representing the infrastructural development, by summing capital expenditure on Power, Telecommunication, Transportation and other Productive Capacity or utilities.

$\mathrm{Ut}=$ Errortem

\section{Model II}

$\mathrm{Y}=\mathrm{f}(\mathrm{t}, \mathrm{y}, \mathrm{fin} / \mathrm{y}, \mathrm{R}, \mathrm{ms}, \mathrm{f} / \mathrm{y}, \mathrm{Infl}, \mathrm{DPS})$.

The OLS linear regression equation based in the above functional relation was express as:

GRGDP $=\beta 0+\beta 1()+\beta 2()+\beta 3 \mathrm{R}+\beta 4 \mathrm{Ms}+\beta 5()+\beta 6$ Infl $+\beta 7 \mathrm{DPS}+$ et $\ldots$

$($ ) = Index of Financial Globalization Proxied as ratio of FDI to RGDP

$\mathrm{R}=$ Exchange Rate in nominal value

Ms = Money supply in nominal value

$(\mathrm{FY})=$ Ratio of fiscal deficit/surplus (fiscal blance) to RGDP

Infl = Inflation Rate

DPS = Degree of Political Stability.

A prior expectations of signs of parameters were stated below:

$\beta 0>0 ; \beta 1>0 ; \beta 2>0 ; \beta 3>0 ; \beta 4>0 ; \beta 5>0 ;$ and $\beta 6<0$.

\section{Hypothesis Testing}

In this part it will be demonstrate the empirical testing of the study: with the

H 1: Economic Globalization cause income inequality within Mali.

$\boldsymbol{H} 2$ : Economic Globalization does not lead to economic growth of Mali

Estimation Techniques and Data Sources

Equation 4 and 6 were estimated by the Ordinary Least Square (OLS) method through E-views software 7.0. The annual time series data for this study are source from World Bank Development Indicators (2017), the ministry of finance and industry and National Bureau of Statistic of Mali (2017).

\section{Presentation and Discussion of Result}

This section presents the result of the OLS for the model as specified in equation 4 and 6 . The result are presented in table 4.1 and 4.2 as estimated trough 7.1 E-view computer packages. 


\section{Model}

- Ieg Gini tradegdp fdigdp dps fiscalbalance capitalgdp

\begin{tabular}{|c|c|c|c|c|}
\hline Souroe & 55 & $\mathrm{df}$ & \multicolumn{2}{|l|}{ Wurber of ohs = } \\
\hline & & & $\mathbb{2}\left(\begin{array}{ll}5 & 51\end{array}\right.$ & $=4$. \\
\hline Wodel. & 113.372074 & $5 \quad 22.6744147$ & Prob $>\mathrm{P}$ & $=0.016$ \\
\hline Aesitual. & 43.2552998 & 94.80614442 & B-squared & $=0.723$ \\
\hline & & & Adf A-squaned & $=0.5$ \\
\hline Total. & 156.627373 & 1411.1876695 & Boot WGE & $=2.19$ \\
\hline
\end{tabular}

\begin{tabular}{|c|c|c|c|c|c|c|}
\hline Gini & Coef. & Std. Brr. & $\mathrm{t}$ & $D|t|$ & \multicolumn{2}{|c|}{ [958 Coof. Intemal]. } \\
\hline tradegitp & $.15 B 3312$ & .0920667 & 1.72 & 0.120 & - . 049041 & .3666157 \\
\hline folight & -.4742016 & .3647213 & -1.30 & 0.226 & -1.293059 & .3500551 \\
\hline dps & .1339082 & 2.460302 & 0.05 & 0.958 & -5.431863 & 5.6068 \\
\hline fiscalbalanoe & -5696544 & .1512443 & -3.77 & 0.004 & -.9117928 & -.27516 \\
\hline capitalgd & .5223205 & .1198414 & 4.36 & 0.002 & .251220 & .793426 \\
\hline ors & 17. BB3B2 & 7.55259 & 2.37 & 0.042 & .7906765 & 34.9697 \\
\hline
\end{tabular}

From the above table, the result of the regression analyses reveal that the coefficient of determination (R-squared) is $72.38 \%$, that is say that the explanatory variables explained a total variation of $72.38 \%$ in the dependent variable (Income Inequality).

This implies that the widening income inequality was as a result of the presence of included explanatory variable such as economic globalization, poor infrastructure facilities, and political instability in Mali between 2000 and 2017. In addition, the coefficient value of fiscal balance of -0.57 also revealed that the government policies taken within the research time frame had been helpful in reducing income inequality in Mali. The other included repressors in this model have a positive sign which implies that trade, degree of political stability (DPS) and capital expenditure have a positive relationship with income inequality in Mali between 2010 and 2017. This implies that the presence of trade, weak democracy, and lack of adequate infrastructural facilities like good road networks; efficient transportation and communication services all contributed adversely to a raising income inequality between the rich and the poor in Mali. 


\section{Model II}

- reg Bgdp tradegdp fidigdp exchangerate as fiscalbalance inf dps

\begin{tabular}{|c|c|c|c|c|c|}
\hline Source & SS & df & MS & \multicolumn{2}{|l|}{ Durber of obs = } \\
\hline & & & & & \\
\hline Model & 73.2211865 & 7 & 10.4601695 & $\operatorname{Prob}>\mathbb{R}$ & $=0.3449$ \\
\hline Residual & 53.5289735 & 7 & 7.64699621 & R-squared & $=0.5777$ \\
\hline & & & & Adj R-squared = & $=0.1554$ \\
\hline Total & 126.75016 & 14 & 9.05358286 & Root MSE & $=2.7653$ \\
\hline
\end{tabular}

\begin{tabular}{|c|c|c|c|c|c|c|}
\hline Rgdp & Coef. & Std. BrI. & $\mathrm{t}$ & $\mathrm{P}|\mathrm{t}|$ & I951 Conf. & Interval] \\
\hline tradegdp & .1556978 & .1301797 & 1.20 & 0.271 & -.1521284 & .4635239 \\
\hline fdigdep & .1393878 & .5268285 & 0.26 & 0.799 & -1.106364 & 1.385139 \\
\hline exchangerate & . 0003103 & .0128293 & 0.02 & 0.981 & -.0300261 & .0306467 \\
\hline Is & $=-1748917$ & .2720095 & -0.64 & 0.541 & -. B180919 & .4683086 \\
\hline fiscalbalance & .1039788 & .0855895 & 1.17 & 0.279 & -.105502 & .3134597 \\
\hline inf & $=1090744$ & .2506988 & -0.44 & 0.677 & $=.7018828$ & .483734 \\
\hline $\mathrm{dps}$ & 4.672904 & 3.225398 & 1.45 & 0.191 & -2.953949 & 12.29976 \\
\hline cons & -5.415761 & 14.1268 & -0.38 & 0.713 & -38.82034 & $27.988 B 2$ \\
\hline
\end{tabular}

The table above shows that the coefficient of determination (R-square) of the model II is 0.578 which implies that the explanatory variable explained a total variation of $57.8 \%$ in the dependent variable (growth rate of GDP) in Mali. On a priori ground, only money supply and inflation rate have a negative sign which indicates that there is negative relationship between them and economic growth in Mali. This implies that money supply and inflation rate have contributed toward reducing economic growth in Mali between 2010 and 2017. The other included regression in this model have a positive sign which implies that trade, foreign direct investment (FDI), exchange rate, fiscal balance, and degree of political stability (DPS), all have a positive relationship with income inequality in Mali between 2010 and 2017. This implies that they contributed adversely to a raising economy growth in Mali.

\section{Table I and II:}

Therefore, it was concluded empirically that economic globalization causes widening income inequality and reduces economic growth in the Malian economy due to much emphasis on financial globalization rather than trade globalization as well as macroeconomic imbalances such as poor governance, political instability inadequate infrastructural facilities and others but to mention few between 2000 and 2016, the phenomenon of globalization has impact on growth, income and employment in most developing countries especially in Mali it as expected that globalization would cause a great increase in production and indirectly lead to development. This means that globalization would lead to an increase in production followed by social welfare. Instead, it has benefited the rich and further widened inequalities between industrialization and poor countries. The problems of unemployment and poverty have not been eradicated in Mali during the era of globalization. 


\section{Policy Implications}

The implementation of real institutional and political reforms, and especially of true legal means to guarantee their application, is essential to build competitive productive capacities, only capable of giving Mali its deserving place within the global economy. Mali holds huge reserves of raw materials: it is potentially rich and yet it is anomalous that the country is among the least developed. The absence or weak of infrastructure in all areas including the area of communication makes it difficult to establish links with the outside world. Proficiency in information technology and communications in now a key factor in promoting development. Mali must make some efforts in that way. Small and medium businesses need information because they do not know the global markets. It is necessary to create or increase the required level of real structures of information for innovation, which would promote greater entrepreneurship. Mali is a reservoir in approximation of 18 million individuals in which youth is the majority, and already is benefiting from its population. The wealth of any nation is first and foremost its human potential. In this sense, Mali is well endowed, but it remains to use a great deal of efforts to bring the youth of the country to the required level by the economic stakes of the new era this human potential should be well educated, well trained, and should know more about the new technologies and above all be well equipped for the economic integration of Africa into the global economy, that means Mali should invest more on education, in other words, government should increase the financial allocation to education in order to expand knowledge. It should improve the quality of education system by improving financial management in the Ministry of Education, recruiting, training and management of teachers are key issues. The government must ensure that it builds strategies that respond to the expectations of Malian families, and realistic plans to implement them. Education plays a major role in the development of any nation. It is when the government is ready, able and willing to expand knowledge that Mali will benefit from globalization.

Mali should protect its culture. This can be achieved through the exhibition and staging of arts and festival. Mali is rich in culture, the promotion of positive values, co-operation understanding peaceful co-existence should be encouraged, through the teaching of social studies. Social studies should be made compulsory at all levels of education. Furthermore, the indigenous mode of dressing should be encouraged and promoted to make use of the traditional dress. The government should be committed to the promotion of positive growth and development. This can be done by looking inward and pulling resources together to enhance growth and development. Mali must anchor its growth prospects in the development of human capital, physical infrastructure, and strong institutions. It must foster the development of the private sector and the macroeconomic environment needed for the private sector to be viable. It should have good governance that stresses accountability and transparency and the development of institutions, the civil service, a sound banking system, and a trustworthy and independent judiciary.

Mali can learn a lot from Asia particularly China's development strategy. Asia benefited from its openness to the entire world and achieved enviably stable per capita income growth of 5 percent and above, with a few downturns, and a remarkable decrease in the incidence of poverty. This progress was due to the importance the Asian countries attached to education and technology, an export-oriented strategy, a sound macroeconomic environment, and high saving and investment rates. Mali should concentrate on primary products, where it has a comparative advantage, the promotion of manufacturing and export of manufactured products will be required for Mali to achieve rapid productivity growth. A comparative advantage in manufacturing would be a launching pad into Mali economy.

\section{Conclusion}

The advances which have been made in communication, travel, and information services in the last fifty years or so make has largely been out of reach for Mali and Many African countries. Many of the effects of social globalization have already hit Mali, since the demand for raw materials has increased among many countries, social globalization has more disadvantages than benefits. One negative results is that natural resources are depleted at a faster rate, another drawback is the violation of human rights, as many countries can exploit human labor outsourced from developing countries. Many scholars think that social globalization is a method for more the advances which have been made in communication, travel and information services in the last 20 years or so make globalization inevitable.

\section{References}

Acosta O. and Gonzalez J.I. (2010). “A thermodynamic approach for emergence of globalization”, in Deng K. G. (ed.) Globalization - Today, Tomorrow. Croatia: Sciyo.

Eregha, P. B. and Irughe I. R. (2009). "Oil Induced Environmental Degradation in theNigeria's Niger Delta: The Multiplier Effects.” Journal of Sustainable Development in Africa, 11 (4) 
Mohammad Abo Gazleh Globalization and Politics: The Effects of globalization on human life aspects. University of Malaya, 2001.

ShermainMannah "The impact of globalization in Africa and the response of trade unions: The case of South Africa" Education Desk South African Democratic Teachers Union Labour Education 2001/2 No. 123

KaramoNimaga. . The Effects of Globalization on African Culture and Education.African and Middle eastern cultures .7 July 2008

Bréhima Kassibo Socio-Economic Effects of Gold Mining in Mali. Eyolf Jul-Larsen ,CMI, R 2006: 4

Dr. Olubukola S. Adesina, The Negative Impact of Globalization on Nigeria, Department ofPolitical Science, University of Ibadan ,Vol. 2 No. 15; August 2012

.S.IbiAjayi," What Africa Needs to Do to Benefit from Globalization", Finance \& development, December 2001 Volume 38, Number 4

Isabel Günther, La croissance pro-pauvres au Mali, Université de Göttingen, Allemagne, AFD 2007

MamadouCamara,Economy\&Economic Development,ibpusa 2007

UNDP ,2014 Human Development Report,Post 2015 Development goals sabel Günther, La croissancepro-pauvres au Mali, Université de Göttingen, Allemagne, AFD 2007

NidhyKhajuria.Globalization ,Scribd,4/23/13 Globalization - Wikipedia, the free encyclopedia

Bréhima Kassibo Socio-Economic Effects ofGold Mining in Mali. Eyolf Jul-Larsen,CMI, R 2006: 4

ShermainMannah "The impact of globalization in Africa and the response of trade unions: The case of South Africa" Education Desk South African Democratic Teachers Union Labour Education 2001/2 No. 123

World Bank, Country Assistance Evaluation, November 12, 2007

Glenn Brigaldino,Managing European Aid Resources in Mali, Afrikainstitutet, 1997

Eugad Manual, Dialogue and Criticism of aid. Section 1: Informing and Setting the Vision.September 2011

Brian Tomlinson,Development Effectiveness, Ibon Books, 2012

OECD, External Debt Statistics ,Glossary of Statistical Terms,Washington DC., 2003. 